Photometer for MEASURING THE SCOTOPIC CANDLEPOWERS

of Self-Luminous Ophthalmic Test Objects

must not be forgotten, of course, that catgut diminishes in strength in the wound, and therefore a margin must be allowed for depreciation.

I have no experience of the use of cotton thread, the figures being inserted for comparison only.

All of us have been annoyed by silk threads pulling out of the eye of a needle during interrupted suturing. The plastic surgeons knot the silk just behind the needle to counter this. The knot catches too much on the conjunctiva or cornea for ophthalmic use, and I would like to draw attention to the ingerious method of pushing the needle through the silk behind the eye of the needle, described by Meyer and Wiener, at the beginning of their textbook ${ }^{8}$. I have found this method most practical, and in conversation that colleagues who have read the book, have completely overlooked the first few pages.

\title{
REFERENCES
}

1. Dunnington, J. H., and Wheerer, M. C.-Proc Amer. Acad. Ophthal. and Otol., October, 1941.

2: Foster, J., Pemberton, E. C., Freedman, S. S.-Trans. Ophthal. Soo. U.K., 1942, p. 320.

3. JAMESON, P. C:-Arch. of Ophthal., Vol. LI, p. 441 ; Vol. VI, p. 329 ; Vol. XXI, p. 362. 1922, 1931, 1939.

4. Speakman, J. B.-Personal Communication, 1940-1944.

5. LANCASTER, W. B.-Amer. Jl. Ophthal., Vol. XXIV, p. 48.4.

6. MEAD and OChSNER,-" "Surgery," Ap. 1940, p. 485.

7. Localio, CASALE and Hinton.-Internat. Abs. of Surg., December, 1943, p. 457 .

8. Wiener, M. and Alvis, B. Y.-W. B. Saunders Co... Phila., Pa., 1939. Surgery of the Eye, p.p. 19-20.

\section{PHOTOMETER FOR MEASURING THE SCOTOPIC CANDLEPOWERS OF SELF-LUMINOUS OPHTHALMIC TEST OBJECTS}

BY

W. S. Stiles, D.Sc.

(THE NATIONAL PHYSICAL LABORATORY)

\begin{abstract}
A PHOTOMETER is described with which the scotopic candlepowers of very feeble light sources (down to about $10^{-9}$ candle) can be measured. Smàll spots of radium paint, 2 or $3 \mathrm{~mm}$. in diameter and having candlepowers in the range covered, are now used (Livingston) to plot the dark-adapted visual field, and the present photometer was designed primarily for their calibration. The radium paint emits green light but the instrument can be used for
\end{abstract}


measurements of scotopic candlepowers of any colour. By tests on colour filters whose scotopic transmission factors can be calculated from their spectral transmission curves, it is shown that the photometer does, in fact, compare lights on the basis of the scotopic visibility curve of the eye, provided the conditions' of measurement are those indicated.

\section{Introduction}

In recent researches by Livingston* and other ophthalmologists, the field of vision of the dark-adapted eye has been explored using as test object a spot of radium paint of about $3, \mathrm{~mm}$. diameter mounted at the centre of a small metal disc. The photometer described in this note was constructed for the measurement by a visual method of the very low candlepowers of such self-luminous test objects.

The instrument employs the principle of Maxwellian view and is very similar to the low brightness photometers of Fabry and Buisson, Gehlhoff and Schering, Collier and others, which were designed for determinations of star magnitudes, atmospheric transmissions, etc. The measurement consists essentially of a comparison of the candlepowers of the test object and a standard source of the same size, by a substitution method.

As the self-luminous ophthalmic test objects are used for tests on the dark-adapted eye, it is appropriate for the comparison with the standard to be made at a low photometric field brightness by a fully dark-adapted abserver. The intensities of most of the test objects are so low that any visual comparison must be made under these conditions. The candlepowers so obtained are not then the ordinary photometric (or photopic) candlepowers but scotopic values. A suitable definition of scotopic candlepower is laid down in this note. Measured values of the scotopic candlepowers of various coloured lights obtained by inserting colour filters in front of a white source are compared with the values computed from the spectral energy distribution of the source, the spectral transmission curve of the filter and the mean scotopic visibility curve of the eye.

\section{Description of the Instrument}

The optical lay-out is shown in Figure la: A standard source is provided by a small circular aperture $\mathrm{A}$ in a brass plate $\mathrm{Q}$ mounted on a larger plate $P, 4.5 \mathrm{~cm}$. in front of a sheet of flashed opal glass $O$. The edge of the aperture is bevelled to give the

"Livingston, P. C.- "Visual problems of aerial warfare," Moynihan Lectures. The Lancet, July 8 and 15, 1944: 
aperture a precisely defined area. The opal is illuminated from behind by a light source $S_{1}$ (uniplanar 'filament, 4 volt, $: 4$ watt) placed at a suitable distance $d$ and run at such a voltage that the light from it, after diffuse transmission by the opal, has a colour temperature of 2,360 deg. $\mathrm{K}$. From preliminary determinations of the candlepower $I$ of the lamp and of the diffuse transmission factor $\tau$ of the opal, the candlepower $i$ of the aperture $A$ in the axial direction can be calculated, given the diameter $a$ of the aperture and the distance $d$. We have,

$$
i=\pi\left(\frac{a}{2}\right)^{2} \cdot \frac{I \tau}{\pi d^{2}}
$$

for example, if $I=2.0$ candles, $\tau=0.60$

$$
\begin{aligned}
& a=3.0 \mathrm{~mm} .\left(=9.8 \times 10^{-3} \mathrm{ft} .\right) \\
& d=12.0 \mathrm{ft} .
\end{aligned}
$$

then $i=2 \cdot 0 \times 10^{-7}$ candle

In measuring a given test object a standard aperture $\mathrm{A}$ is selected which has a diameter approximately equal to and in any case not exceeding that of the luminous area of the test object. Eight standard apertures of diameters in steps from 1 to $4 \mathrm{~mm}$. cover the required range. The test object is substituted for the standard source by extinguishing the lamp $S_{1}$ and fixing the test object on the plate $\mathbf{P}$ so that its luminous area $\mathrm{T}$ tåkes the place of aperture $\mathrm{A}$.

The plate $\mathrm{P}$ and opal $\mathrm{O}$ form a unit which can be moved on a length of optical bench to bring the test object $\mathrm{T}$ or aperture $\mathrm{A}$ - to the focus of the lens $L_{1}$. The light from. $T$ or $A$ is rendered parallel by $L_{1}$ and that half of the beam which is not obstructed by the mirror $M$ is brought to a focus by the lens $L_{2}$ (power $4 \mathrm{D}$.) in the plane of the eye-ring $R$. The power of the lens $L_{1}$ is such that the image of the test object in $R$ has a diameter equal approximately to $4 \mathrm{~mm}$. and in any case does not exceed this value. Thus the lens $L_{1}$ must be chosen to suit the particular test objẹct; a set of lenses of powers increasing in steps from 4 to $16 \mathrm{D}$. covers the necessary range.

At the brightness levels used in the measurements, the natural pupil of the eye has a diameter considerably greater than $4 \mathrm{~mm}$., so that an eye $\mathrm{E}$ applied to the eye ring $\mathrm{R}$ collects all the light in the image of $A$ or $T$ and sees one half of the lens $L_{2}$ uniformly illuminated from that source. The other half of the lens is illuminated in a similar way with light from the comparison aperture $A_{2}$ (diameter $2 \mathrm{~mm}$.), an image of which, $4 \mathrm{~mm}$. in diameter, is formed in the plane of $R$ by the lenses $L_{2}$ and $L_{3}$ (power, 8D.) by way of an intermediate reflexion at the front aluminised mirror M. The very low brightness required for aperture $A_{2}$ is obtained 
by reducing the light from the comparison source $S_{2}$ by transmission through a small aperture $A_{1}$ and diffusion at the opals $\mathrm{O}_{1}$ and $\mathrm{O}_{2}$. The focussing and centering of the images of the apertures $\mathrm{A}, \mathrm{A}_{2}$ and of the test object are facilitated by inserting in $\mathrm{R}$ a tube carrying an eye-piece (Fig. 1b) with which the focal plane of the lens $L_{2}$ may be examined. A neutral wedge $W$ (Ilford, clear, density gradient : $Q^{\circ} 125 \mathrm{~cm}$.) controls the intensity of the comparison beam, and is adjusted by the observer to bring the two halves of the lens $L_{2}$ to equality of brightness.

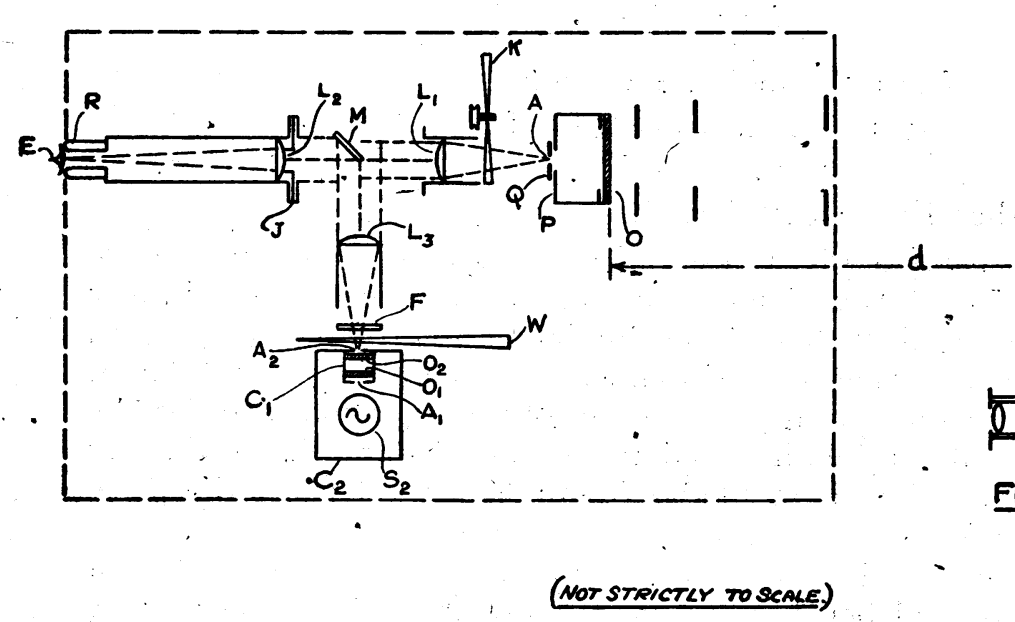

Fia.la.

An iris diaphragm $J$ fitted to the lens $L_{2}$ enables the apparent field size of the photometer to be varied. If $z$ is the diameter of the iris expressed in $\mathrm{cm}$. the angular diameter of the field is

$$
\frac{z .}{25} \times 57.3 \mathrm{deg} \text {. }
$$

A maximum angular diameter of 8 deg. is obtainable.

The intensity of the test or standard half of the field can be reduced by a known factor by inserting a calibrated.sector disk $\mathrm{K}$.

\section{Definition of Scotopic Candlepower}

The candlepower of the standard aperture computed in the way described above is the photometric or photopic candlepower. In principle this is derived from a visual comparison with the standard candle by an ideal eye whose relative spectral sensitivity curve (visibility curve) is an internationally agreed average curve 


\section{- PHotometer for MEASURING THE SCOTOPIC CANDLEPOWERS of Self-Luminous Ophthalmic Test Objects}

for the eye in the light-adapted or photopic state. The agreed curve is the C.I.E. (1924) Standard Visibility Curve and this curve is implied whenever an ordinary photometric magnitude such as candlepower, brightness, illumination, is specified.

Sources having the same photometric (photopic) candlepower but different energy distrißutions do not in general appear equally intense to an eye in the dark-adapted or scotopic state. This is because, on dark-adapting the eye, its spectral sensitivity curve is modified, the main change being a displacement of the curve towards the blue (Purkinje effect). At present there is no internationally agreed scotopic visibility curve but a mean curve* based on the results of several investigations has been adopted by the Vision Committee (Flying Personnel: Research Committee, Air Ministry). To complete the description of scotopic candlepower, brightness, illumination, etc., a unit of scotopic candlepower must be laid down. In accordance. with present practice this unit is so chosen that for "white" light having the same spectral energy distribution as a Planckian radiator of temperature $2360 \mathrm{deg} . \mathrm{K}$, the scotopic and photometric (photopic) candlepowers have the same numerical value: Thus, in this note, by scotopic value will be understood the value based on the Vision Commit- tee's scotopic visibility curve and on a unit of scotopic candlepower which makes scotopic and photometric quantities agree for $2360 \mathrm{deg}$. white.

\section{Conditions of Measurement}

The conditions of measurement with the present photometer are designed to give values approximating to the scotopic values. With this object, the photometric field is large (about $8 \mathrm{deg}$. diam.), bipartite, centrally divided, and of low brightness. The observer is kept well dark-adapted. Normally he makes matches while fixating on the centre of the vertical dividing line. A greater sensitivity can usually be obtained by fixating on the top point of the dividing line or even on a point on the dividing line produced upwards. If an observer adopts such a procedure he must adhere to it throughout. A dévice for interchanging the test and comparison lights in the right and left hand halves of the field would be desirable but is not incorporated in the present instrument.

In making a measurement, the test object is set up on plate $P$ and the wedge is adjusted to give a match with the comparison source. The standard aperture is then substituted for the test

\footnotetext{
*Stiles, W. S. and Smith, T., "A mean scotopic visibility curve," Proc. Phys Soc., Vol. LVI, p. 251, 1944.
} 
object and, by suitable choice of the sector $K$, its effective candlepower is adjusted so that on making a match the wedge reading is very nearly the same as that obtained with the test object. This ensures that the test and standard matches are made at approximately the same field brightness.' Knowing the gradient of the wedge (determined-in situ by matches with the standard aperture in conjunction with various sectors $K$ ), the candlepower of the test object is calculated by the usual photometric methods.

Save in the special case when the colour of the test light is 2360: deg. white, the answer so obtained will be the scotopic candlepower only if the field brightness and general matching - conditions including observer characteristics are such that the standard scotopic visibility curve is operative. The possibility of error through failure to get just the right conditions is greatly reduced by inserting colour filters over the standard and comparison sources, to make their colours (strictly their spectral energy distributions) agree as closely as possible with that of the test object. The spectral transmission curve of the colour filter in front of the standard source being known, its scotopic transmission factor $T_{\text {vs }}$ for $2360 \mathrm{deg}$. white can be calculated, using the relative energy distribution of $2360 \mathrm{deg}$. white and the scotopic visibility curve. The scotopic candlepower of the standard aperture $\mathrm{A}$ with the filter in position is then its candlepower $i$ multiplied by TVs. If the energy distributions of the test light and of the standard light plus filter agreed exactly, the special precautions to ensure matching under scotopic conditions would be unnecessary. In practice, it is not generally possible to obtain a perfect agreement and these precautions must be observed.

By comparing the calculated scotopic transmission of the colour filter with the transmission measured on the photometer an indication is obtained of the extent to which correct scotopic conditions of measurement have been achieved. In measuring the transmission a match is first made with the colour filter in front of the standard source, the comparison field being white. The colour filter is then removed and a sector $K$ inserted to give approximately the same wedge reading. Thus the two readings from which the transmission is derived are obtained at nearly the same photometric field brightness.

Most of the self-luminous test objects measured up to now have emitted a green light which is roughly matched in energy distribution by filtering the $2360 \mathrm{deg}$. white through a Board of Trade Light Green Glass. The calculated scotopic transmission of the glass used and its value measured in the photometer at several field brightnesses are shown in the following Table. 
PHOTOMETER FOR MEASURING THE SCOTOPIC CANDLEPOWERS of Self-Luminous OpHThalmic Test Objects 635

TABLE I.-B.O.T. Light Green Glass No 505.

Calculated scotopic transmission for Plancliàn radiation at $2360^{\circ} . K=36^{\circ} 8^{\circ}$ per cent.

Calculated photometric transmission for Planckian radiation at $2360^{\circ} \mathrm{K}=1665$ per cent.

\begin{tabular}{|c|c|c|c|c|}
\hline \multirow{3}{*}{$\begin{array}{l}\text { Brightposs-of photo- } \\
\text { metric field (2360 } \\
\text { white seen through } \\
\text { purpil of } 4 \mathrm{~mm} \text {. diam.) }\end{array}$} & \multicolumn{4}{|c|}{ Measured transmission } \\
\hline & \multicolumn{2}{|c|}{ Observer } & \multirow{2}{*}{ Mean* } & \multirow{2}{*}{$\begin{array}{l}\text { Mean * for } 13 \\
\text { other observer: }\end{array}$} \\
\hline & A & B & & \\
\hline $\begin{array}{c}\text { e.f.c. } \\
5.9 \times 10^{-5} \\
1.4 \times 10^{-4} \\
3 \cdot 7 \times 10^{-4} \\
4 \cdot 9 \times 10^{-4} \\
7 \cdot 8 \times 10^{-4} \\
1 \cdot 7 \times 10^{-3} \\
3 \cdot 7 \times 10^{-3} \\
9 \cdot 8 \times 10^{-3} \\
2 \cdot 1 \times 10^{-2} \\
3.8 \times 10^{-2}\end{array}$ & 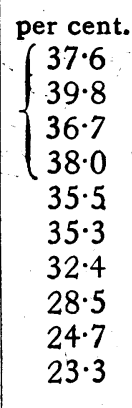 & 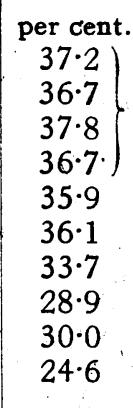 & $\begin{array}{l}- \\
\div \\
- \\
-\end{array}$ & $\begin{array}{c}\text { per cent. } \\
= \\
- \\
= \\
= \\
= \\
-\end{array}$ \\
\hline
\end{tabular}

* Means computed from corresponding densities.

TABLE II

\begin{tabular}{|c|c|c|c|c|c|c|c|}
\hline \multirow{4}{*}{ Filter } & \multirow{4}{*}{$\begin{array}{c}\text { Scotopic } \\
\text { Dominant } \\
\text { Wavelength } \\
\text { (for } 2360^{\circ} \mathrm{K} \\
\text { white) }\end{array}$} & \multirow{4}{*}{$\begin{array}{c}\text { Photometric } \\
\text { (photopic) } \\
\text { transmission } \\
\text { calculated } \\
\text { for } 2360^{\circ} \mathrm{K}^{-} \\
\text {white }\end{array}$} & \multicolumn{5}{|c|}{ Scotopic transmission for $2360^{\circ} \mathrm{K}$ white } \\
\hline & & & \multicolumn{4}{|c|}{ Measured } & \multirow{3}{*}{ Calculated } \\
\hline & & & \multicolumn{3}{|c|}{ Observer } & \multirow{2}{*}{ Mean } & \\
\hline & & & A & B & C & & \\
\hline & $\mathbf{m} \mu$ & per cent. & & & & & per cent. \\
\hline Deep blue... & 460 & $\begin{array}{l}0 \cdot 15 \\
7 \cdot 37\end{array}$ & $\begin{array}{l}1 \cdot 79 \\
16.4\end{array}$ & $\begin{array}{r}1.95 \\
15 \cdot 0\end{array}$ & $\begin{array}{r}2 \cdot 00 \\
15 \cdot 6\end{array}$ & $\begin{array}{r}1.91 \\
.15 .6\end{array}$ & $\begin{array}{l}1.94 \\
15.9\end{array}$ \\
\hline Daylight ... & 505 & $19 \cdot 7$ & 37.5 & 38.5 & $33 \cdot 5$ & $36 \cdot 4$ & 37.9 \\
\hline Blue green & 510 & - $9 \cdot 35$ & $24 \cdot 8$ & $25 \cdot 5$ & $26: 7$ & $25 \cdot 5$ & $25: 9$ \\
\hline Dark green & 515 & $10 \cdot 9$ & $28 \cdot 5$ & $29 \cdot 0$ & $24 \cdot 1$ & $27 \cdot 1$ & $27 \cdot 6$ \\
\hline Sap green ... & 530 & $11 \cdot 1$ & $15 \cdot 4$ & $17 \cdot 2$ & $15 \cdot 0$ & $15 \cdot 8$ & $15: 2$ \\
\hline $\mathrm{Na}$ yellow... & 545 & $75 \cdot 8$ & $38: 2$ & 39.6 & 39.9 & $39 \cdot 2$ & $37 \cdot 5$ \\
\hline Amber $\quad \ldots$ & 550 & $25 \cdot 7$ & $11 \cdot 8$ & $11 \cdot 9$ & $12 \cdot 0$ & 11.9 & $11 \cdot 5$ \\
\hline Dark orange & 580 & $42 \cdot 9$ & $9 \cdot 82$ & $9 \cdot 66$ & $9 \cdot 77$ & $9 \cdot 75$ & $10 \cdot \theta$ \\
\hline Red $\quad \ldots$ & 630 & $9 \cdot 74$ & 0.68 & 1.66 & 0.64 & 0.98 & 0.64 \\
\hline
\end{tabular}

* Means computed from the corresponding densities. 
At field brightnesses below about $5 \times 10^{-4}$ e.f.c. (2360 deg. white seen through pupil of $4 \mathrm{~mm}$. diam.) the measured scotopic transmission is sensibly constant and agrees very closely with the computed value. The conclusion is that for comparisons of white and light greens, the conditions of photometric matching correspond well to those implied in the definition of scotopic candlepower provided the field brightness does not exceed $5.0 \times 10^{-4}$ e.f.c. At higher field brightnesses the measured transmission diminishes

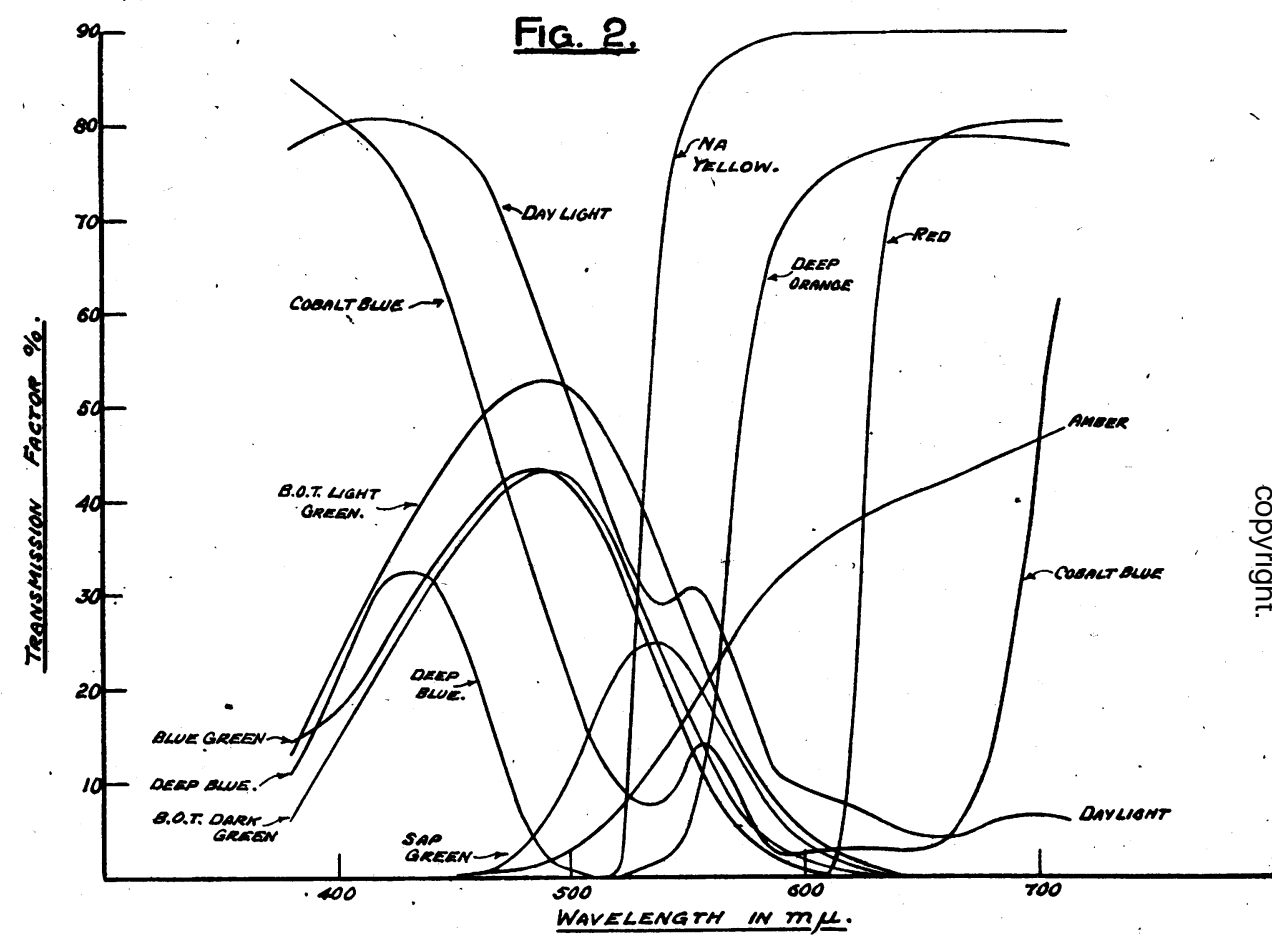

and approaches the photopic value, although this is not reached with the range of brightnesses available in the photometer.

The results of tests on other colour filters all made at a field brightness of approximately $5.0 \times 10^{-4}$ e.f.c. $(2360 \mathrm{deg}$. white through $4 \mathrm{~mm}$. pupil) are summarised in Table II.

The spectral transmission curves of the various filters used are plotted in Fig. 2.

On the whole, the observed and computed scotopic values agree well. Measurements with the red filter were the most difficult and show the largest difference between observed and calculated 
values. It may fairly be concluded that provided the energy distribution of a given test object is roughly matched by choosing a suitable colour filter whose computed scotopic transmission is known, an experimental comparison of the test object with the filtered light will give the scotopic value of the test object with satisfactory accuracy, probably to within \pm 12 per cent., except possibly for red test objects. This is true provided the photometric match is made at a scotopic brightness of about $5.0 \times 10^{-4}$ e.f.c. $(4 \mathrm{~mm}$. diam. pupil) and the result is the mean for at least two " normal " observers.

Acknowledgement

This paper is published by permission of the Director, The National Phyșical Laboratory.

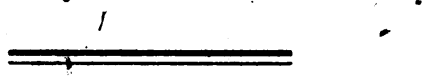

\section{ANNOTATION}

\section{Social and Medical Problems of Phlyctenular Disease in Dublin}

This is the title of the Montgomery Lecture, given by Dr. J. B. McArevey, in Dublin on May 3,1944; in which the author reviews the historical, medical, social and statistical aspects of the problem. Speer in 1822 found "a vast and complicated mass of disease" among the poor, which perhaps was more abundant than in any city of equal size and population in Europe. He attributed the high incidence of disease to social conditions, especially poverty "and overcrowding in the slums. Strumous ophthalmia was first reported in Ireland by Ryan of Kilkenny in 1824. Two years later Isaac Ryal gave Ireland its first accurate description of the disease.

Dr. McArevey concludes that the results of his study demonstrate " that basically phlyctenular disease is a manifestation of malnutrition. It is a disease of the poorer class-those whose main source of food is bread and cereals, and from whose diet the essential proteins necessary to growth and normal development are practically absent; the only source of these available to most of them is milk, and that only in limited quantities-in many cases, in the form of free milk. As a necessary concomitant, the affected children suffer from a low grade malnutritional anaemia, with a deficiency of some of the essential vitamins. It is difficult to see how it could be otherwise, in view of the results of my social enquiry, and the facts elicited by the statistical investigations, which reveal the disturbing conclusion that the incidence of the disease, omitting the temporary increase due to the war conditions, has not radically changed since Ryal's day. At this stage one cannot fạil to recall his clinical 